\title{
The Metalinguistic and Linguistic Knowledge Tests and Their Relationship between Non-native In-service and Pre-service Teachers
}

\author{
Saeideh Ahangari (Corresponding author) \\ Department of English, Tabriz Branch, Islamic Azad University, Tabriz, Iran \\ E-mail: saeideh.ahangari@gmail.com \\ Morteza Abdi \\ Department of English, Tabriz Branch, Islamic Azad University, Tabriz, Iran \\ E-mail: mortaza.abdii@yahoo.com
}

Received: $21-04-2017$

Published: 01-11-2017
Accepted: 05-06-2017

doi:10.7575/aiac.ijalel.v.6n.6p.246
Advance Access Published: September 2017

URL: http://dx.doi.org/10.7575/aiac.ijalel.v.6n.6p.246

\begin{abstract}
Fairly recently, the construct of metalinguistic knowledge and its relation to L2 learners' language proficiency have been the focus of numerous theoreticians, researchers, and the educators in the field. With respect to second language teachers assessment, however, little attempt has been made to explore the metalinguistic knowledge and its relationship between serving and non-serving teachers. The current study, accordingly, was designed to investigate whether there is a relationship between non-native in-service and pre-service teachers performing the metalinguistic and linguistic knowledge tests and if there is a difference between the two groups of teachers' performance on these two tests. To collect the data on the two constructs of linguistic and metalinguistic knowledge, 80 non-native teachers performed on the Cloze Test and untimed Grammaticality Judgment Test from an English language institute. Following a range of statistical analyses, the findings revealed no positive correlation between the Linguistic and Metalinguistic tests both in the in-service and pre-service teachers of English language. It was also found that the two groups of teachers did not differ significantly with respect to their performance on the Linguistic test while the in-service teachers outperformed their counterpart in the Metalinguistic knowledge test.
\end{abstract}

Keywords: linguistic knowledge, metalinguistic knowledge, in-service teacher, pre-service teacher, cloze test, grammaticality judgment test

\section{Introduction}

Quite recently, Metalinguistic Knowledge (MK) has been considered as a vital component of second language (L2) teaching and learning and has occupied the minds of quite a number of researchers (e.g., Berry, 2005, 2014; DeKeyser, 2009; Ellis, 2004; Hu, 2010; Roehr, 2008) in the field. Despite the diversity of definitions for the construct of MK in the literature, Roehr (2007) defines MK as "the learners' ability to correct, describe, and explain L2 errors" (p. 174). Drawing on $\mathrm{Hu}$ (2002) and Ellis (2009), the concept of MK has been particularly defined as a learner's explicit knowledge which potentially encompasses the L2 features of syntax, morphology, phonology, and pragmatics at both the subsentential and suprasentential level. To achieve the intended purposes, the two definitions informed the framework of our study.

Recent second language acquisition (SLA) research has explored the construct of MK in relation to L2 learners' language proficiency. Additionally, it has uncovered a positive, but mostly moderate, relationship between learners' L2 MK in the sense of correction, description, and explanation ability, and their L2 proficiency as measured by means of various written or oral tests (Roehr, 2007). The construct of MK as well as its assessment methods, however, are yet unknown with respect to language teachers. To gain sufficient insight into non-native language teachers' MK, a strong need is hence felt to conduct further studies with respect to assessment approaches.

An essential point of distinction has to be made here with respect to concepts of MK and metalinguistic awareness. Masny (1987) defines metalinguistic awareness as an "an individual's ability to match, intuitively, spoken or written utterances with his or her knowledge of language" (p. 59). While metalinguistic awareness encompasses implicit and intuitive knowledge, the construct of MK is explicit, declarative, and analytical in nature that a learner possesses about a given language (e.g., Anderson 2005; Hulstijn 2005).

Since MK tends to be analyzed and necessitates a purposeful attentional concentration, the theorists and researchers in the field argue that: a) learners equipped with MK will be aware of their underlying knowledge of a particular language, b) MK is verbalizable; that is, learners are potentially capable of verbalizing the rules of L2 grammar (Butler, 2002), c) 
MK can be learnable at any stage (Bialystok, 1994), and eventually, d) MK may not be readily accessible in the context of language use (Elder, 2009).

\subsection{MK Assessment and Grammaticality Judgment Tests}

The construct of MK has witnessed considerable debate in the literature and continues to be explored in depth via theorists, researchers, and educators of L2. One point of critical significance, accordingly, is how to assess MK. That is, L2 researchers tend to seek for tests which can satisfactorily operationalize the construct of explicit knowledge of learners. One kind of popular test employed by numerous, recent studies (e.g., Bley-Vroman \& Joo, 2001; Montrul, 2005; Toth, 2006) is Grammaticality Judgment Tests (GJTs). Ellis (1991) defines GJT as a task in which learners "decide whether a sentence is well-formed or deviant" (p. 162).

To perform GJTs, according to Elder (2009), participants follow the three steps of (a) semantic processing, (b) noticing, and (c) reflecting in order to complete the intended process. Furthermore, Renou (2001) views GJTs significant because (1) they reflect information about learners' knowledge of the grammar; (2) they provide information about the development of learning L2 and (3) they provide information about the ways in which knowledge is organized (Gass, 1983). It is therefore safe to argue that GJTs have the potential to assess the nature of MK construct so that one can obtain sufficient insight into a learner's underlying grammar knowledge of a language given. Moreover, a number of studies (e.g., Inagaki, 2001; Nabei \& Swain, 2002) have highlighted the influential features of GJTs as regards the type of knowledge participants can access while performing the judgment.

\subsection{Literature Review}

Although there are a large number of empirical studies (e.g., Berry, 2009; Elder \& Manwaring, 2004; Ellis, 2005; White \& Ranta, 2002) asserting strong correlations between learners' MK and their L2 proficiency, research directly exploring the relationship between components of language learning aptitude, MK, and the role of these notions with regard to L2 proficiency is as yet scarce (Hu, 2010; Roehr, 2007).

The study reported by Myhill (2000) on the MK of learners' grammar suggests that learning MK can be made problematic and a further research is felt essential primarily for teachers' MK and later for learners' acquisition of MK. Using a picture description task, White and Ranta (2002) investigated the relationship between French-speaking learners' metalinguistic task performance and their oral production in terms of the possessive determiners 'his/her' in English. Their study found that there was considerable correlation between oral and metalinguistic task performance for the Comparison class whereas the instructional intervention appeared to modify the relationship between performances on the two tasks in the Rule class.

Following this line of enquiry, $\mathrm{Hu}$ (2002) examined psychological factors that influence access to MK in L2 production. Employing a range of tasks with 64 adult Chinese learners of English, he concluded that there are chief psychological restrictions on the application of MK in L2 performance. Hu (2011), in another endeavor, reported 76 Chinese learners of English who completed a verbalization task of grammar. Exploring the relationship between L2 learners MK and metalanguage, his analyses demonstrated a positive relationship between MK and metalanguage with respect to explicit grammar instruction.

Roehr (2007) reported on a study which investigated the relationship between a narrowly focused measure of L2 proficiency and L2 language-analytic ability into a measure of MK. The study revealed a strong and significant correlation between knowledge of L2 grammar and vocabulary and L2 MK. In addition, the results of a principal components analysis demonstrated that the ability to correct, describe, and explain highlighted L2 errors and the ability to recognize the grammatical role of parts of speech in L2 sentences appear to be parts of the same multi-componential construct. Another investigation by Berry (2009) found that the learners were, to a great extent, different in their knowledge of 50 items of metalanguage and that this knowledge was significantly correlated with their top grades in English, indicating a correlation between knowledge of language and proficiency in English. Eventually, Correa (2011) investigated the relationship between MK and subjunctive accuracy by learners of Spanish at three levels. While MK was assessed via a set of four terminology and GJTs both in English and Spanish, mastery of the Spanish subjunctive was evaluated through a set of five receptive and productive tasks. The findings revealed that 2) there was a positive correlation between English MK and Spanish MK as well as a positive correlation between MK and accuracy in the use of the subjunctive.

\subsection{Statement of the Problem}

The construct of MK, undoubtedly, plays a pivotal role in L2 learners' language proficiency and it assists the learners to attend the language features more consciously. In addition, SLA researchers and theorists have explored the essential ways (i.e. GJTs) to assess L2 learners' understanding of the given language features. The literature reviewed lends support to the efficacious role of MK knowledge in language proficiency and that GJTs tend to generate more optimal outcomes in assessing L2 learners' knowledge of MK. With respect to teachers' MK, however, little attempt, if any, has been made to explore its relationship with Linguistic Knowledge (LK). In-service Teachers (INSETs) are undeniably required to possess not only the LK of a given language but the MK as well. An essential question raised here is whether GJTs as a popular Metalinguistic Knowledge Test (MKT) generate more satisfactory results than Linguistic Knowledge Tests (LKTs) in the assessment of teachers' underlying grammar knowledge of English language. Another point of interest is whether the two tests function inevitably different from each other in the INSETs. More importantly, whether the two tests produce identical results with respect to Pre-service Teachers (PRSETs) and whether the PRSETs differ significantly with the INSETs are yet unknown. To the best of our knowledge, no attempt has been made to 
explore the relationship between the MKTs (i.e. as a form of GJTs) and LKTs with respect to teachers' performance in a foreign context. Therefore, the present study is designed to explore if a relationship exists between the LKT and MKT in non-native Iranian INSET and PRSET teachers and whether non-native Iranian teachers perform differently on these two tests. Specifically, this study aims to address the following research questions:

\subsection{Research Questions:}

R.Q. 1. Is there a significant relationship between the LKT and MKT in the INSET group?

R.Q. 2. Is there a significant relationship between the LKT and MKT in the PRSET group?

R.Q. 3. Is there a significant difference between the INSET and PRSET performances on the LKT?

R.Q. 4. Is there a significant difference between the INSET and PRSET performances on the MKT?

\section{Method}

\subsection{Participants}

A total of 80 English language teachers participated in our study. Since our study aimed to take the effect and role of teaching experience into account, the participants were divided into either in-service or pre-service teacher groups. That is, 40 teachers serving as English language instructors were assigned as our INSET group and another 40 teacher participants who were assigned as our PRSET group were planning to become English language teacher in the upcoming year. All the participants were majoring in teaching English as a foreign language (TEFL) from Iranian universities with either Turkish or Persian as their native languages. While the INSET group had been teaching English language for a couple of years in Iranian institutes, the PRSET group did not possess any teaching experience.

\subsection{Instruments}

Two teacher-made tests were employed as the major instruments in our study, that is, LKT and MKT:

\subsubsection{LKT}

To operationalize the construct of LK, a Cloze Test (CT) was utilized. The passage selected from a sample of TOEFL (pbt version) reading passages for $\mathrm{CT}$ included 15 items. For each item, the teacher participants were required to fill in the blanks with appropriate grammatical features. A range of L2 features from English language grammar were included in the test. An attempt was also made to test those grammatical features which our participants had frequently encountered in advance.

\subsubsection{MKT}

For the operationalization of MK, however, a 15-item GJT was employed. Since the primary purpose was to explore the correlation between LKT and MKT, every attempt was made to make the two tests as much parallel with respect to L2 features and number of items as well. In addition, the two groups were provided with unlimited time to perform on GJT, hence untimed GJT. The rationale underlying the employment of unspeeded GJT was to allow the teacher participants to perform all the three operations of semantic processing, noticing, and reflecting. It is argued that administering GJTs under time constraints may affect the type of knowledge that test takers access in making their responses. Timed GJTs may encourage test takers to draw more on implicit knowledge; in contrast, untimed GJTs can allow them to access more explicit knowledge (Bialystok, 1979; Elder, 2009). To ensure the teacher participants' application of their MK, they were initially required to identify the ungrammatical option from among the four underlined choices and then provide the well-formed feature for each item. For each item, we assigned two points both in LKT and MKT.

\subsection{Procedure}

The design of the study was correlational including an in-service and a pre-service group of teachers. The former held several years of experience teaching English language; yet, the latter was preparing to teach in the upcoming year. In this study, an attempt was made to explore the correlation between the INSETs and PRSETs regarding their performance on LKT and MKT. To begin with, the devised LKT and MKT were piloted with similar group of teachers prior to their administration to ensure their reliability. A reliability of 0.81 and 0.83 were achieved for LKT and MKT respectively. Following this, LKT was administered to the INSET and PRSET groups to gain insight into their linguistic knowledge of grammar and their performance was rated based on the established criteria. As the third stage, MKT was administered to two groups of the study with three weeks interval to avoid any potential test effect on MKT. The obtained scores for the performance of the INSETs and PRSETs, eventually, were submitted to statistical analyses for possible correlations between the two tests in the INSET and PRSET and potential differences between the two groups of the study in LKT and MKT.

\section{Results}

\subsection{The LKT and MKT in the INSETS}

The first research question addressed the relationship between the LKT and MKT in the INSETs. To answer the question, Pearson correlation coefficient was calculated to see whether there was any statistically significant correlation between the LKT and MKT. Table 1 depicts the relationship between the two tests. 


\begin{tabular}{cll}
\hline Table 1. Pearson correlation coefficient between LKT and MKT in the INSETs \\
\hline & MKT-GJT \\
\hline LKT-CT & Pearson Correlation & -.294 \\
\hline & Sig. (2-tailed) & .065 \\
\hline $\mathrm{N}$ & 40
\end{tabular}

**Correlation is significant at the 0.01 level (2-tailed).

As indicated in the Table, the correlation between the LKT and MKT ( $\mathrm{r}=-0.294, p=0.065)$ was not statistically significant at level one for the INSETs. That is, there was no correlation between the performance of the INSETs on the LKT and MKT.

\subsection{The LKT and MKT in the PRSETS}

The relationship between the LKT and MKT in the PRSETs was addressed in the second research question. To measure this, another Pearson correlation coefficient was calculated to realize whether there was any statistically significant correlation between the LKT and MKT in prosperous teachers. Table 2 illustrates the relationship between the two tests.

Table 2. Pearson correlation coefficient between LKT and MKT in the PRSETs

\begin{tabular}{lll}
\hline & & MKT-GJT \\
\hline LKT-CT & Pearson Correlation & .101 \\
\hline Sig. (2-tailed) & .534 \\
\hline $\mathrm{N}$ & 40
\end{tabular}

**Correlation is significant at the 0.01 level (2-tailed).

The table shows that there was no correlation between the PRSETs performance on the LKT and MKT $(\mathrm{r}=0.101, p=$ 0.534). That is to say, the PRSETs performance on the LKT and MKT did not reveal any statistically significant relationship between the two.

\subsection{The INSET and PRSET in the LKT}

An Independent Samples $t$-test was run to understand whether there is a significant difference between the performances of the INSETs and PRSETs on the LKT which was the focus of third research question. Table 3 indicates the statistical difference between the two groups.

Table 3. Descriptive Statistics and Independent Samples t-test for the LKT in the INSET and PRSET

\begin{tabular}{lcccccc}
\hline & Mean & $\mathrm{N}$ & $\mathrm{Std}$ & $\mathrm{t}$ & $\mathrm{df}$. & Sig. \\
\hline The INSET Group & 22.62 & 40 & 2.99 & 1.87 & 78 & 0.06 \\
\hline The PRSET Group & 21.3 & 40 & 3.32 & & & \\
\hline
\end{tabular}

The obtained results revealed that the INSETs outperformed the PRSETs in the LKT with a mean score of 22.62 and 21.3 respectively. However, the two groups did not differ significantly in performing the LKT $(p=0.06)$.

\subsection{The INSET and PRSET in the MKT}

To answer the fourth research question, another Independent Samples $t$-test was calculated for any significant difference between the performances of the INSETs and PRSETs on the MKT. Table 4 illustrates the existing differences between the two groups of teacher participants in detail.

Table 3. Descriptive Statistics and Independent Samples t-test for the MKT in the INSET and PRSET

\begin{tabular}{lcccccc}
\hline & Mean & $\mathrm{N}$ & $\mathrm{Std}$ & $\mathrm{t}$ & df. & Sig. \\
\hline The INSET Group & 22.07 & 40 & 2.96 & 2.52 & 78 & 0.01 \\
\hline The PRSET Group & 20.42 & 40 & 2.89 & & & \\
\hline
\end{tabular}


The results from the descriptive statistics indicated that the INSETs demonstrated a better performance on the MKT in comparison with the PRSETs. The mean score was 22.07 for the former group while the latter had a mean score of 20. 42. That is to say, the INSETs outperformed the PRSETs with respect to the MKT and there was a statistically significant difference between the two groups of the study $(p=0.01)$.

\section{Discussion}

The current study, initially, sought to investigate whether there are significant correlations between the performances of the non-native INSETs and PRSETs on CT and GJT as indicators of LK and MK, respectively. This was addressed by the first and second research questions and accordingly two Pearson Correlation Coefficients were run to unveil the potential relationships.

The findings, however, did not reveal any statistically significant correlations between CT and GJT both in the INSETs and PRSETs. Although majority of the studies (e.g., Berry, 2009; Elder et. al., 2004; Ellis, 2005; White et. al., 2002) conducted on L2 learners' MK suggested strong correlations between learners' MK and their L2 proficiency; our study failed to find any relationship with respect to the non-native teachers' MK. Our finding is not also consistent with that of Roehr (2007) who revealed a positive correlation between English MK and Spanish MK as well as a positive correlation between MK and accuracy in the use of the subjunctive. This study failed to support the findings obtained by Correa (2011) who suggested a strong and significant correlation between knowledge of L2 grammar and vocabulary and L2 MK. Eventually, our results are not in line with those of $\mathrm{Hu}$ (2011) who demonstrated a positive relationship between MK and metalanguage in terms of explicit grammar instruction. The mastery of LK in a given language, therefore, cannot ensure non-native teachers' display of their explicit knowledge (i.e., MK) of that language. MK, to be more specific, tends to function quite differently among L2 learners and teachers which might be a feasible explanation for the inconsistency of the findings on MK.

In addition, the teaching experience in the INSETs does not appear to make them metalinguistically aware of a particular language. Butler (2002) argues that MK is verbalizable; that is, learners are potentially capable of verbalizing the rules of L2 grammar. Despite their teaching experience on L2 grammar, Non-native INSET teachers failed to display this MK knowledge. This might be argued in the way that the display of MK differs between language learners and teachers. Although teaching experience can arm the teachers with a satisfactory LK, their MK is felt to be fostered via other metalinguistic activities. It seems to us that in order to assist the serving and prospective teachers to employ their MK of a particular language, mere LK cannot pave the intended route; but rather, teachers can be made metalinguistically aware through explicit instruction and regular assessment of their explicit knowledge about the underlying system of the language they teach. This is also feasible through occasional workshops during which the serving and prospective teachers could be provided with sufficient knowledge of language and ample opportunities to explicitly display their LK, hence making them aware.

In another endeavor, our study was designed to explore the different performances that the INSETs and PRSETs display on CT and GJT. The third and fourth research questions addressed whether the two groups differ significantly on their performances in LKT and MKT. No group outperformed the other with respect to LKT and hence their performance did not reveal any significant differences. To explain this finding, Elder (2009) argues that MK may not be readily accessible in the context of language use. Additionally, $\mathrm{Hu}$ (2002) concludes that there are chief psychological restrictions on the application of MK in L2 performance. Therefore, the context of language use as well as relevant psychological limitations can account for the non-native teachers' failure in displaying their knowledge of MK.

Teaching experience, to reiterate, does not appear to practically assist the serving teachers in performing better than the non-serving ones and the two groups can manifest quite equal performance on CT as the indicator of LK. With respect to MKT, however, the INSETs outperformed the PRSETs and hence their difference was statistically significant. This is great evidence for the effective role that teaching experience can and should engender in teachers' MK. This finding lends support to the study reported by Myhill (2000) on the MK of learners' grammar. She suggests that learning MK can be made problematic and a further research is felt essential primarily for teachers' MK and later for learners' acquisition of MK. The INSETs, in comparison with the PRSETs, are seemingly more capable of manifesting their explicit knowledge of grammar and providing an appropriate explanation for the ungrammaticality of language features.

\section{Conclusion}

Considering the findings obtained, therefore, it is safe to argue that LK and MK do not tend to be correlated among nonnative teachers unless an intervening medium is introduced between the two constructs. Drawing on the debates and arguments regarding teacher development, explicit instruction during teacher training courses as a direct intervention is capable of making teachers metalinguistically aware. Furthermore, alternative assessments of teachers' LK and providing them with opportunities to reflect on their underlying system of language can enable them to be more conscious of and to widen the developing grammar to achieve the required expert knowledge.

\section{References}

Anderson, J. R. (2005). Cognitive Psychology and its Implications (6th edn). New York, NY: Worth Publishers.

Berry, R. (2005). "Making the most of metalanguage", Language Awareness, 14(1), 3-20.

Berry, R. (2009). EFL majors' knowledge of metalinguistic terminology: a comparative study. Language Awareness, $18(2), 113-128$. 
Bialystok, E. (1994). Analysis and control in the development of second language proficiency. Studies in Second Language Acquisition, 16, 157-168.

Bley-Vroman, R., and Joo, H. R. (2001). The acquisition and interpretation of English locative constructions by native speakers of Korean. Studies in Second Language Acquisition, 23(2), 207-219.

Butler, Y. (2002) Second language learner' theories on the use of English articles: An analysis of the metalinguistic knowledge used by Japanese students in acquiring the English article system. Studies in Second Language Acquisition, 24, 451-480.

Correa, M. (2011). Subjunctive accuracy and metalinguistic knowledge of L2 learners of Spanish. Electronic Journal of foreign Language teaching, 8(1), 39-56.

DeKeyser, R. (2009). Cognitive-psychological processes in second language learning. In: Long, M.H., Doughty, C.J. (Eds.), The Handbook of Language Teaching. Wiley-Blackwell, Malden, MA, pp. 119-138.

Elder, C. (2009). Validating a test of metalinguistic knowledge. In R. Ellis, S. Loewen, C. Elder, R. Erlam, J. Philp, and H. Reinders, Implicit and explicit knowledge in second language learning, testing and teaching. pp. (113-138).

Elder, C. and Manwaring, D. (2004). The relationship between metalinguistic knowledge and learning outcomes among undergraduate students of Chinese'. Language Awareness, 13, 145-162.

Ellis, N. (2005). At the interface: Dynamic interactions of explicit and implicit knowledge. Studies in Second Language Acquisition, 27, 305-352.

Ellis, R. (1991). Grammaticality judgments and second language acquisition. Studies in Second Language Acquisition, 13 (2), 161-186.

Ellis, R. (2004). “The definition and measurement of L2 explicit knowledge”, Language Learning, 54(2), $227-275$.

Gass, S. (1983). The development of L2 intuitions. TESQ Quaterly, 17(2), 273-291.

$\mathrm{Hu}$, G. (2002). Psychological constraints on the utility of metalinguistic knowledge in second language production. Studies in Second Language Acquisition, 25 (3), 347-386.

Hu, G. (2010). Revisiting the role of metalanguage in L2 teaching and learning. EA Journal, 26(1), 61-70.

Hu, G. (2011). Metalinguistic knowledge, metalanguage, and their relationship in L2 learners. System, 39, 63-77.

Hulstijn. J. (2005). Theoretical and empirical issues in the study of implicit and explicit second language learning: Introduction. Studies in Second Language Acquisition, 27, 129-140.

Inagaki, S. (2001). Motion verbs with goal PPs in the L2 acquisition of English and Japanese. Studies in Second Language Acquisition, 23(2), 153-170.

Masny, D. (1987). The role of language and cognition in second language metalinguistic awareness. In J.P. Lantolf and A. Labarca (eds). Research in Second Language Learning: Focus on the Classroom (pp. 59-73). Norwood, NJ: Ablex.

Montrul, S. (2005). On knowledge and development of unaccusativity in Spanish L2. Linguistics, 43 (6), 1153-1190.

Myhill, D. (2000). Misconceptions and difficulties in the acquisition of metalinguistic knowledge. Language and Education, 14 (3), 151-163.

Nabei, T., and Swain, M. (2002). Learner awareness of recasts in classroom interaction: A case study of an adult EFL student's second language learning. Language Awareness, 11(1), 43-63.

Renou, J. (2001). An examination of the relationship between metalinguistic awareness and second-language proficiency of adult learners of French. Language Awareness, 10, 248-267.

Roehr, K. (2007). Metalinguistic knowledge and language ability in university-level L2 learners. Applied Linguistics, 29, 173-190.

Roehr, K. (2008). Linguistic and metalinguistic categories in second language learning. Cognitive Linguistics, 19 (1), 67-106.

Toth, P. (2006). Processing instruction and a role for output in second language acquisition. Language Learning, 56, 319-385.

White, J., \& Ranta, L. (2002). Examining the interface between metalinguistic task performance and oral production in a second language. Language Awareness, 11(4), 259-290. 